\title{
Saúde mental infantojuvenil: avaliação de formação continuada junto a professores de
} sala de recursos multifuncionais

\section{Children and Adolescents' mental health: evaluation of continuing education with multifunctional resource room teachers}

\section{Salud mental infantil y juvenil: evaluación de la formación continua de profesores de aulas de recursos multifuncionales}

\author{
Recebido: 18/11/2020 \\ Aprovado: 01/06/2021 \\ Publicado: 21/08/2021
}

\section{Carolina Elisabeth Squassoni ${ }^{1}$ Sarah Raquel Almeida Lins ${ }^{2}$ Thelma Simões Matsukura ${ }^{3}$}

Este é um estudo transversal exploratório, descritivo e quantiqualitativo realizado em 2016, em dois municípios do interior paulista, com objetivo de avaliar uma proposta de formação continuada para professores de salas de recursos multifuncionais, com foco na temática da saúde mental infanto-juvenil no contexto escolar. Para a coleta de dados foram utilizados dois questionários que buscaram caracterizar os participantes e avaliar a proposta de formação continuada. Participaram 51 professoras e a formação foi desenvolvida em encontros presenciais e atividades à distância, durante seis meses, totalizando 30 horas. Os resultados revelaram que $98 \%$ dos participantes avaliaram positivamente a oportunidade e indicaram contribuições para a prática escolar na atuação junto ao aluno e a família, indicando também a importância da participação de professores de salas de aula regulares. A formação continuada mostrou fornecer ferramentas para maximizar oportunidades de permanência e aprendizado de crianças em sofrimento psíquico na escola.

Descritores: Educação especial; Educação; Educação continuada; Saúde mental.

This is an exploratory, descriptive and quanti-qualitative cross-sectional study carried out in 2016, in two municipalities in the interior of the state of São Paulo, Brazil. It aimed to evaluate a proposal for continuing education for teachers in multifunctional resource rooms, focusing on children's mental health in the school environment. For data collection, two questionnaires were used that sought to characterize the participants and assess the proposal for continuing education. 51 teachers participated. Training was developed in in-person meetings and distance activities, for six months, making a total of 30 hours. The results showed that $98 \%$ of participants gave the opportunity a positive evaluation and indicated contributions to the school practice in the performance with the student and families, also indicating the importance of participation of teachers from regular schools. Continuing education has been shown to provide tools to maximize permanence and learning opportunities for children in psychological distress at school.

Descriptors: Education, Special; Education; Education, Continuing; Mental health.

Este es un estudio exploratorio, descriptivo y cuanti-cualitativo de corte transversal realizado en 2016 en dos municipios del interior del estado de São Paulo, Brasil, con el objetivo de evaluar una propuesta de formación continua para profesores de aulas de recursos multifuncionales, centrado en el tema de la salud mental infantil y juvenil en el contexto escolar. Para la recogida de datos se utilizaron dos cuestionarios que pretendían caracterizar a los participantes y evaluar la propuesta de formación continua. Participaron 51 profesoras y la formación se desarrolló en encuentros presenciales y actividades a distancia, durante seis meses, totalizando 30 horas. Los resultados revelaron que el $98 \%$ de los participantes evaluaron positivamente la oportunidad e indicaron las contribuciones a la práctica escolar en el desempeño con el estudiante y la familia, indicando también la importancia de la participación de los profesores de las aulas regulares. La formación continua demostró proporcionar herramientas para maximizar las oportunidades de permanencia y aprendizaje de los niños en sufrimiento psíquico en la escuela.

Descriptores: Educación especial; Educación; Educación continua; Salud mental.

1. Terapeuta Ocupacional. Mestre e Doutora em Educação Especial. Pós-Doutora em Terapia Ocupacional. Centro de Atenção Psicossocial II da Secretaria Municipal de Saúde de São Carlos, SP, Brasil. ORCID: 0000-0002-0830-6667 E-mail: carolinasquassoni15@gmail.com

2. Terapeuta Ocupacional. Especialista em Docência do Ensino Superior. Mestre em Terapia Ocupacional. Doutora em Educação Especial. Associação Renascer - Centro de Reabilitação e Integração, São José do Rio Preto, SP, Brasil. ORCID: 0000-0001-5271-728X E-mail: sarahlinsto@gmail.com

3. Terapeuta Ocupacional. Especialista em Terapia Ocupacional em Psiquiatria. Mestre e Doutora em Saúde Mental. Pós Doutora em Saúde Pública. Professora Titular do Departamento de Terapia Ocupacional e do Programa de Pós-Graduação em Terapia Ocupacional da Universidade Federal de São Carlos, SP, Brasil. ORCID: 0000-0003-3812-3893 E-mail: thelma@ufscar.br 


\section{INTRODUÇÃO}

$\mathbf{0}$

campo da educação foi marcado por um histórico de práticas discriminatórias que tinham como foco um alunado padrão, no entanto o advento do formato inclusivo amplia o enfrentamento e a superação paulatina. Para isso, a escola passou por uma série de ajustes estruturais, culturais e sociais de modo que as novas ações envolvam maior participação dos alunos que, antes excluídos, passaram a ter o direito à educação e ao prosseguimento da vida social e profissional ${ }^{1,2}$.

Dentre ações e políticas que procuram dar respaldo às premissas da inclusão escolar, temse as salas de recursos multifuncionais (SRM). As SRM são espaços destinados para o atendimento educacional especializado ${ }^{3}$, e desempenham função primordial para a entrada, permanência e o processo educativo de alunos que demandam intervenções específicas no contexto escolar.

Como é de conhecimento, a política de inclusão brasileira ainda não contempla as crianças que apresentam outras formas de transtornos mentais não identificados dentro dos transtornos do espectro do autismo ${ }^{4,5}$. Nesse sentido, a escola tem convivido com alunos em sofrimento psíquico, se pautando majoritariamente sob a perspectiva de laudos médicos e uso de medicamentos 6,7 .

A Organização Mundial da Saúde aponta a escola como uma instituição que tem o potencial tanto de agir como de contribuir para a promoção da saúde mental das crianças e adolescentes, podendo atuar como suporte para a identificação, encaminhamentos para setores de tratamento específico, e em alguns casos, prestar serviços de tratamento primário ${ }^{8}$.

No entanto, estudos nacionais e internacionais que focalizam a situação dos professores frente aos problemas de saúde mental de seus alunos, indicam que há pouca informação disponível para os professores; que eles se sentem inseguros para tomar decisões a respeito de alunos com transtornos mentais; e que demonstram interesse em adquirir conhecimentos na área, pois consideram que as informações podem ser úteis no dia a dia com os alunos, tanto em relação ao seu aprendizado quanto para orientar os pais e colegas de turma ${ }^{5,9-12}$.

Um estudo nacional publicado no ano de $2014^{11}$ da rede estadual do município de São Paulo identificou a percepção e interesse de professores, mostrando que a falta de informações sobre a saúde mental gera insegurança e dificulta a prática cotidiana, e que há interesse em ter mais acesso e materiais que abordassem a temática.

Outro estudo brasileiro ${ }^{12}$, que desenvolveu um programa de educação interativa, baseado na web, para ajudar professores do ensino fundamental no reconhecimento e no manejo em sala de aula de crianças com possíveis transtornos mentais, apontou que a realização de programas de capacitação para professores é uma estratégia positiva que pode auxiliá-los tanto na identificação como na vivencia cotidiana da criança com um possível problema de saúde mental.

Em um estudo português ${ }^{10}$, com 257 professores, a partir da premissa de que a escola é um contexto privilegiado para a criação de um ambiente favorável à saúde, verificou-se que após a formação, os docentes se sentiam mais preparados para identificar sinais de problemas relacionados à saúde mental em seus alunos, além da adoção de posturas mais empáticas, ouvintes e direcionadas para serviços adicionais necessários.

A promoção de conhecimento sobre saúde mental infantil junto aos professores é uma potente estratégia para auxiliá-los em sua prática cotidiana ${ }^{9-16}$. Assim, este estudo teve como objetivo avaliar uma proposta de formação continuada para professores de salas de recursos multifuncionais, com foco na temática da saúde mental infanto-juvenil no contexto escolar.

\section{MÉTODO}

Trata-se de estudo quantiqualitativo, descritivo e exploratório ${ }^{17}$ que tem como temática a saúde mental infanto-juvenil e que focaliza a avaliação de uma proposta de formação continuada realizada junto a professores do ensino público. 
Participaram professores de salas de recursos multifuncionais (SRM), atuantes no ensino infantil e fundamental, pertencentes à rede municipal de educação de duas cidades do interior do estado de São Paulo, Brasil. Como critério de inclusão foi considerado o exercício profissional em SRM superior a seis meses e a assinatura do Termo de Consentimento Livre e Esclarecido.

Todas as etapas do estudo foram realizadas nas instalações das Secretarias Municipais de Educação dos dois municípios participantes no ano de 2016.

Para a coleta de dados foram utilizados dois questionários, com aplicações-teste, a saber: - Questionário 1 (Identificação e caracterização dos participantes): abordou-se informações gerais em relação à identificação pessoal e formação profissional.

- Questionário 2 (Avaliação da proposta de formação continuada): avaliou a proposta de formação continuada em relação a: compreensão sobre saúde mental infanto-juvenil (SMIJ), possíveis contribuições da proposta, formato (adequação de conteúdo, duração, temas e abordagens utilizadas), temas mais importantes, segurança para atuação junto às crianças em sofrimento psíquico e levantamento de novas demandas.

A proposta de formação continuada foi composta por oito encontros presenciais e atividades a distância, totalizando 30 horas. Todos os encontros presenciais ocorreram no Horário de Trabalho Pedagógico Coletivo (HTPC), já programado pelas respectivas secretarias e atendendo o horário e a disponibilidade dos professores.

As atividades a distância contemplaram a realização de leituras de textos, indicação de vídeos e elaboração de um diário reflexivo. A cada encontro, as participantes recebiam as atividades a serem realizadas até o encontro seguinte. A frequência mínima de $75 \%$ foi considerada para o aproveitamento dos encontros, conforme estabelecido pelas Secretarias de Educação, o que possibilitou um certificado às participantes.

Quanto ao tratamento e a análise dos dados, as informações obtidas por meio dos instrumentos foram organizadas em planilhas do programa Excel ${ }^{\circledR}$, e os resultados quantitativos foram apresentados descritivamente em tabelas e gráficos.

Os dados qualitativos foram analisados por meio da identificação de categorias de análise de $\operatorname{Bardin}^{18}$, que segue três etapas: 1) pré-análise: que busca a sistematização das ideias iniciais); 2) exploração do material: que enfatiza a construção de operações de codificação por meio do recorte para agregação e enumeração; e, 3) tratamento dos resultados, inferência e interpretação: que capta os conteúdos manifestos e latentes. Assim, depois de repetidas leituras, o conteúdo foi analisado de forma sistemática e organizado em categorias de análise.

Os participantes foram identificados com letras, de acordo com o município de vinculação (município A ou município B), seguido de número específico (conforme a identificação individual de cada participante no estudo).

O estudo foi submetido e aprovado pelo Comitê de Ética em Pesquisa em Seres Humanos

da Universidade Federal de São Carlos, CAAE 55337916.7.0000.5504 e CAAE 57570116.8.0000.5504, e seguiu a resolução noำ66, de 12 de dezembro de 2012, sobre as diretrizes e normas regulamentadoras de pesquisas com seres humanos.

\section{RESULTADOS}

O Município A contava com 57 unidades escolares (25 delas possuíam SRM), referentes ao ensino infantil e fundamental I. O Município B contabilizava 58 unidades educacionais, sendo 14 com SRM nas escolas de ensino fundamental, e nove SRM no Centro de Atendimento Educacional Especializado.

Participaram inicialmente 53 professoras, das quais, 26 do município A e 27 do município B, com resposta após atividade de 51 delas. A Tabela 1 apresenta as informações referentes aos encontros e aos conteúdos abordados ao longo da formação.

Para melhor compreensão, os dados foram divididos em: Caracterização dos participantes; e Participação e avaliação. 
Tabela 1. Encontros presenciais e temas abordados na proposta de formação continuada em SMIJ. São Carlos, SP, 2018.

\begin{tabular}{ll}
\hline Encontro presencial & \multicolumn{1}{c}{ Tema } \\
\hline Encontro 1 & Apresentação da proposta e coleta dos dados iniciais (questionário 1) \\
Encontro 2 & Saúde mental geral e saúde mental infantojuvenil \\
Encontro 3 & Aprofundando a compreensão sobre SMIJ a partir da realidade escolar \\
Encontro 4 & Risco e Proteção ao desenvolvimento infantojuvenil \\
Encontro 5 & O Papel da Escola \\
Encontro 6 & Estratégias de atuação na escola \\
Encontro 7 & Rede de cuidados e de proteção da infância e adolescência \\
Encontro 8 & Encerramento dos encontros e avaliação da formação (questionário 2) \\
\hline
\end{tabular}

\section{Caracterização dos participantes}

Participaram da formação continuada 53 professoras de salas de recursos multifuncionais. Do total de 60 professoras convidadas, 53 efetivaram sua participação na proposta de formação continuada. Dessas, apenas duas não participaram da etapa final e não realizaram a avaliação da formação. Portanto, na fase de avaliação o presente estudo contou com 51 participantes. A Tabela 2 indica a distribuição percentual dos convites e aceites.

Tabela 2. Participantes de SRM (efetivos e desistentes). São Carlos, SP, 2018.

\begin{tabular}{lccc}
\hline Situação & $\begin{array}{c}\text { No de professoras } \\
\text { convidadas }\end{array}$ & $\begin{array}{c}\text { No de participantes na } \\
\text { proposta de formação N (\%) }\end{array}$ & $\begin{array}{c}\text { No de participantes na avaliação da } \\
\text { proposta N (\%) }\end{array}$ \\
\hline Município A & 27 & $26(96 \%)$ & $24(92 \%)$ \\
Município B & 33 & $27(82 \%)$ & $27(100 \%)$ \\
\% (Total) & 60 & $53(88 \%)$ & $51(96 \%)$ \\
\hline
\end{tabular}

Todas as participantes eram do sexo feminino. Quanto à faixa etária, 25 participantes tinham entre 41 e 50 anos, 17 tinham idades entre 31 e 40 anos, seis de 21 a 30 anos e cinco com idades entre 51 a 60 anos.

Quanto à formação, 39 participantes se graduaram em Pedagogia, 10 cursaram Magistério e Pedagogia, uma tinha graduação em Ciências Sociais, uma em Psicopedagogia, uma em Educação Especial, e uma professora não especificou.

Quanto a formação para o trabalho em SRM, todas as participantes deram continuidade à formação específica em áreas da Educação Especial, especialmente em Psicopedagogia, Educação Especial e Educação Inclusiva e Atendimento Educacional Especializado (Gráfico 1).

As áreas de especialização da categoria "outros" foram aquelas citadas uma única vez, sendo elas: Neuropsicologia, Educação e Reabilitação do Surdo, Educação Matemática, Deficiência Mental, Educação Infantil, Educação Ambiental, Administração Escolar e Orientação Educacional, Linguística de Texto e Ensino.

Gráfico 1. Formação complementar das professoras em SRM. São Carlos, SP, 2018.

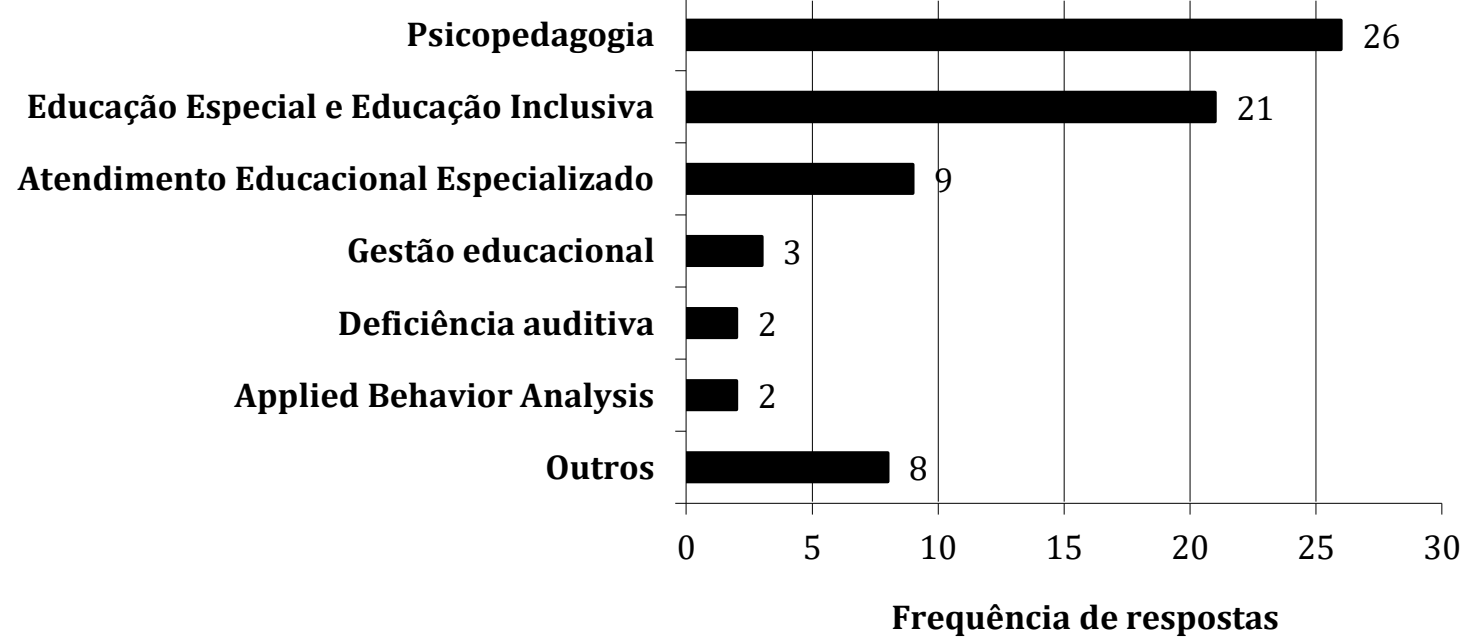




\section{Participação e avaliação}

A média de presença das participantes nos encontros foi de $90 \%$ no município A e $96 \%$ no município B. Na avaliação da formação, os resultados apontaram que $98 \%$ avaliaram a proposta de formação continuada positivamente. As justificavas das avaliações positivas se deram em:

1. Contribuições para o aprendizado (33);

2. Contribuições para o esclarecimento do tema (9);

3. Troca de experiências (3);

4. Abertura e disponibilidade das pesquisadoras (3); e,

5. Contribuição para a formação pessoal (2).

Alguns relatos exemplificam e qualificam os aspectos positivos apontados pelas participantes:

\section{Contribuições para o aprendizado}

Os encontros foram positivos e significativos, pois trouxeram informações sobre saúde mental que eu desconhecia e que vão contribuir para minha prática docente na identificação de alunos e, também, na elaboração de estratégias. (B19)

\section{Contribuições para o esclarecimento do tema}

Os encontros foram produtivos no sentido de podermos verificar que nosso campo de atuação é importante, que fazemos a diferença para muitas crianças e, principalmente, nos trouxe um conhecimento maior do qual tínhamos noção, mas que não tínhamos a dimensão sobre saúde mental e suas implicações. (B21)

\section{Abertura e disponibilidade das pesquisadoras}

Muito produtivos e enriquecedores, sem dúvida. Além disso, destaco a abertura e a disponibilidade das responsáveis pela formação por acolher e discutir as dúvidas e reflexões do grupo. Experiência ímpar no contexto de formação docente. (B11)

Três participantes consideraram que os encontros foram produtivos e enriquecedores especialmente pela oportunidade de reflexão e troca de experiências com os colegas, e a indicação de que falar e aprender sobre saúde mental é importante para a formação do professor.

A avaliação dos encontros indicou contribuições para o cotidiano com os alunos, a saber:

1. Mudanças na forma de ver e de se relacionar com o aluno (24);

2. Replanejamento de ações e de estratégias (21); e,

3. Mudança na relação com a família da criança (2).

Alguns relatos mostram essas contribuições:

Mudança na forma de ver e de se relacionar com o aluno

Através dos encontros foi possível mudar o olhar para determinados alunos com dificuldades de aprendizagem e tentar compreender melhor o contexto em que estão inseridos. (A17)

Replanejamento de ações e de estratégias

De imediato foi possível reformular algumas questões comumente levantadas no cotidiano escolar, proporcionando um novo olhar na atuação com as crianças, principalmente sobre o medo e a insegurança dos alunos com problemas de comportamento. (B27)

\section{Mudanças na relação com a família da criança}

Sim, hoje posso dizer que eu ignorava algumas questões sobre saúde mental, assim como suas causas. Hoje, vejo o quão importante é nosso trabalho junto aos alunos e a seus pais. Percebo a relação escola-família de forma diferente, mais respeitosa, digamos assim! (B21)

Quanto à adequação do conteúdo, a duração dos encontros e frequência; e a apresentação dos temas e abordagens utilizadas, os itens foram avaliados quantitativamente, com notas de um a cinco, sendo: 1 - ruim; 2 - regular; 3 - bom; 4 - ótimo; e, 5 - excelente. A avaliação foi positiva uma vez que a maior parte das notas esteve entre cinco (excelente) e quatro (ótimo).

Tabela 2. Avaliação quanto ao formato da ação de formação continuada. São Carlos, SP, 2018.

\begin{tabular}{|c|c|c|c|c|c|}
\hline Item/ Nota & 5 - Excelente & 4-ótimo & 3-Bom & 2 - Regular & 1-Ruim \\
\hline Adequação do conteúdo & 27 & 19 & 4 & 0 & 1 \\
\hline Duração dos encontros e frequência & 14 & 27 & 9 & 1 & 0 \\
\hline Apresentação dos temas & 28 & 18 & 5 & 0 & 0 \\
\hline Abordagens utilizadas & 19 & 28 & 4 & 0 & 0 \\
\hline
\end{tabular}


Na importância da participação descreveu-se:

Gostei muito e aprendi muito, pois não tinha esse conhecimento, achei rico e vou utilizar na vida profissional e no meu cotidiano. (A10)

Os temas foram abordados com clareza e foram organizados cuidadosamente para uma compreensão mais ampla das implicações da saúde mental infantil desde a percepção de sua existência, até as ações específicas e possíveis na escola e fora dela (rede). (B11)

Os resultados revelam que os professores compreenderam e relacionaram os conteúdos a prática cotidiana, e indicaram a relevância do tema, cuja possibilidade de abordagem e discussão era pequena ou até mesmo inexistente.

As participantes também apontaram que as atividades sugeridas trouxeram enriquecimento à formação, que as discussões realizadas nos encontros proporcionavam maior participação das mesmas, que os diários reflexivos eram uma oportunidade para que elas pudessem se expressar mais profundamente e, ainda, que os textos e vídeos indicados a cada encontro foram significativos:

As atividades extra-presenciais foram de grande valia para acompanhar o assunto discutido, e também para reflexão do nosso trabalho. Os textos, vídeos e diários realizados foram tão bons que pretendo consultar logo que iniciar o próximo ano, relembrando "registros importantes" para meu desenvolvimento pessoal e profissional. (A12)

Especialmente os vídeos, podem ser utilizados em reuniões de pais e em orientações a professores. (B4)

Porém, algumas professoras indicaram que não conseguiram acompanhar as atividades a distância:

Infelizmente não consegui acompanhar e realizar a leitura de todos os textos e vídeos. Pretendo voltar a rever todos em breve. (A19)

A proposta implementada buscou fazer uso de diversas fontes e formatos na composição das atividades individuais e coletivas, realizadas de forma presencial e a distância, por meio de conversas, discussões, diários reflexivos, indicação de textos, vídeos e filmes.

Com a possibilidade de se abordar mais de um item, o Gráfico 2 apresenta a lista dos temas indicados pelas participantes.

Gráfico 2. Temas abordados importantes de acordo com professoras em SMR. São Carlos, SP, 2018.

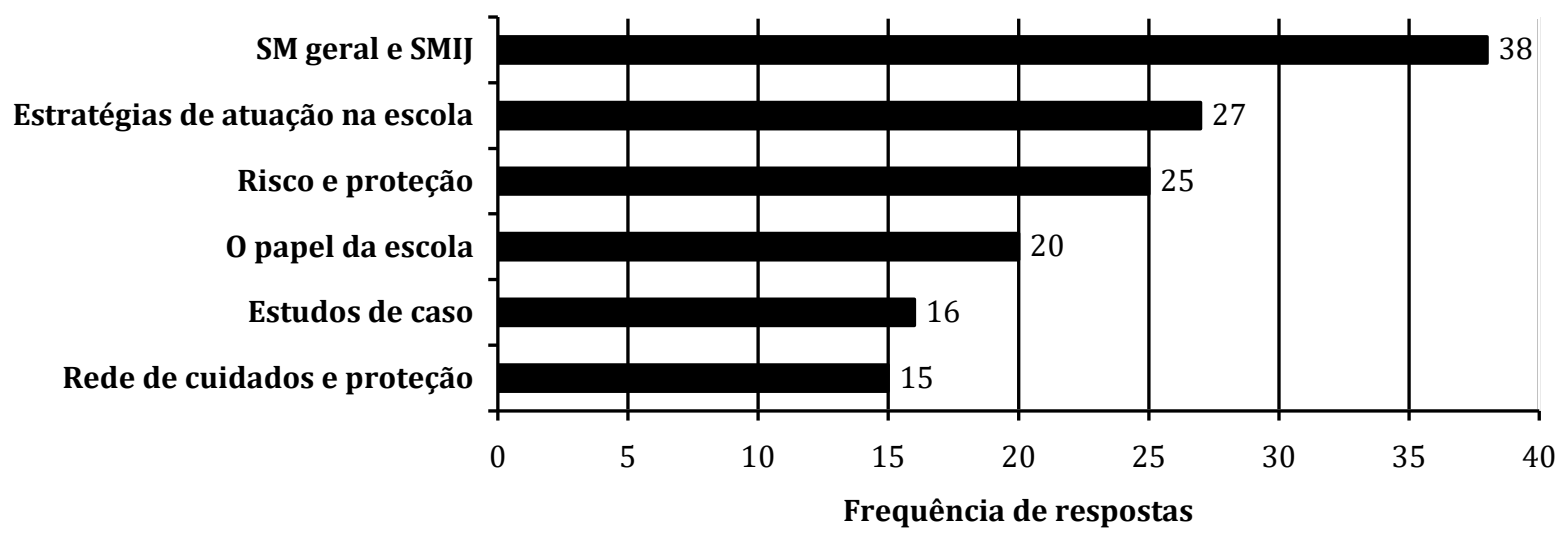

Legenda: $\mathrm{SM}$ = saúde mental; SMIJ = saúde mental infantojuvenil.

As depoentes apresentaram justificativas sobre a importância dos temas:

Importante para a aquisição de conhecimento

O tema geral de saúde mental foi muito enriquecedor e esclarecedor. Pude esclarecer dúvidas em relação a esse tema. A questão do risco e proteção e o papel da escola também foram bem específicos e pude refletir sobre minha atuação profissional. (B16)

Ajuda na prática do cotidiano escolar

Sempre atuei em educação infantil e há 3 anos estou no ensino fundamental. Adorei conhecer sobre este tema tão pertinente em minha escola, assim como conhecer novas estratégias para alcançar esse público. (B4)

Sobre o que gostariam de aprofundar, os temas de maior interesse das professoras foram: estratégias de intervenção (25\%); transtornos específicos (18\%); e saúde mental geral e saúde 
mental infantojuvenil (18\%). Destes, apenas os transtornos específicos não foram abordados na formação. Aponta-se destaques que justificam tais temas:

Acredito que aprofundar as estratégias para resolução de problemas dentro do contexto escolar seria muito interessante. (A17)

Poderia talvez explorar mais as características do autismo relacionadas com o sofrimento psíquico. Também seria interessante conhecermos um pouco sobre esquizofrenia. (B23)

O tema saúde mental infantojuvenil é bastante amplo e poderia continuar a ser trabalhado. (B4)

Em adequações para o aprimoramento da formação, com destaque sugeriu-se: a participação de professores de sala regular $(\mathrm{n}=15)$, conforme as falas:

Um projeto construído com a participação de todos os professores, incluindo a participação do professor da sala regular. (A16)

Estender o curso como está para professoras e diretoras. (B13)

[...] Acredito que os professores que atuam em sala de aula, principalmente do ensino fundamental são os que mais necessitam de curso sobre a saúde mental. (B17)

\section{DISCUSSÃo}

São escassos os estudos que abordam iniciativas de formação em saúde mental infantojuvenil junto a professores, bem como os que apresentam a avaliação da formação e compartilham as experiências ${ }^{19}$. Entende-se que essas formações são estratégias positivas que possibilitam a melhora do conhecimento docente no reconhecimento e na lida junto às crianças em sofrimento psíquico, nos encaminhamentos mais efetivos e, também, na redução do estigma perante a saúde mental ${ }^{1,12,15,16 .}$.

No presente estudo, a proposta de formação foi avaliada positivamente por $98 \%$ das participantes, sendo apontadas as contribuições para a prática escolar na atuação junto ao aluno e a família, a relevância da troca de experiências com outros professores e o reconhecimento da importância de seu papel como professora de SRM, resultados concordantes com outras investigações ${ }^{10,20}$. Especificamente, a realização de programas de formação em saúde mental contribuem para: fortalecimento da autoconfiança, aquisição de competências úteis para resolução de problemas e manejo de situações críticas ${ }^{19}$.

Os resultados aqui encontrados corroboram com os do estudo feito no "Projeto ES'COOL"10 que também indicaram que os professores passaram a adotar posturas mais sensíveis, empáticas e a oferecer mais apoio a seus alunos após a formação.

As professoras indicaram positivamente o conteúdo trabalhado nos encontros, as abordagens utilizadas e a frequência dos encontros. Em relação às atividades à distância, o presente estudo buscou avançar nas propostas apresentadas em outros trabalhos ${ }^{12,16}$ com valorização e benefícios apontados.

Considerando as indicações de formato e de abordagens sugeridas pelas professoras, as avaliações foram positivas, bem como a indicação sobre a realização de consultas posteriores aos materiais sugeridos e o compartilhamento com outros colegas. Esse compartilhamento pode, ainda, sugerir uma possível disseminação do conteúdo apresentado, concordando com a ideia de que o professor é um profissional-chave para disseminação de novas práticas em saúde mental ${ }^{13,16,21}$.

A ordem de temas prioritários sinaliza a necessidade de informação e esclarecimentos sobre saúde mental geral, na medida em que é primária a necessidade de compreensão e a apropriação do conhecimento. Não se trata de tornar o professor um especialista, mas proporcionar aportes para que o educador analise de forma crítica as questões relacionadas à saúde mental, nas necessidades e particularidades do aluno, bem como o desenvolvimento de novas atitudes perante a criança, sua família e a equipe escolar.

Por outro lado, a rede de cuidados e a intersetorialidade aparecem como temas de última prioridade. Tal resultado aponta para o desafio da articulação entre os campos de atuação e cuidado à infância e adolescência, rumo a construção de uma rede de cuidado e de proteção compartilhada, essencial para a identificação mais precoce de situações de sofrimento psíquico, para o encaminhamento para os setores necessários ${ }^{9}$, além de compreender-se que a efetiva 
inclusão exige a implementação do princípio da intersetorialidade 22,23 . São imprescindíveis as discussões e articulações intersetoriais entre profissionais da escola e os de outros setores, como a saúde e assistência social, e estudos futuros devem se aprofundar neste relevante desafio.

Uma das metas da formação oferecida foi de proporcionar reflexões que resultassem em uma compreensão mais ampla sobre a saúde mental infantojuvenil, considerando a prática cotidiana do professor junto aos alunos. E, na medida em que os relatos das participantes apontaram para uma ampliação da reflexão sobre a prática, para o reconhecimento da rede de cuidados e da escola como parte integrante da mesma, para a indicação de mais atenção e abordagem sobre a família e pela avaliação das próprias participantes, é possível que tenha havido um ganho importante para a ampliação das possibilidades de inclusão escolar e para a redução do estigma da saúde mental.

\section{CONCLUSÃO}

A possibilidade de oferecer uma proposta de formação continuada sobre saúde mental infantojuvenil deve maximizar oportunidades de abordagem e problemática junto a professores e gestores de escolas públicas e privadas. A apropriação dos professores sobre esta realidade pode ampliar as oportunidades de aprendizado e de permanência de crianças e adolescentes em sofrimento psíquico na escola.

Indicou-se a inclusão de professores de salas regulares, que não foram alvos do presente estudo, sendo esta uma limitação da pesquisa. Também, a falta de avaliação sistematizada, envolvendo um desenho mais robusto de medidas pode ser outra limitação, uma vez que poderia oferecer maiores elementos sobre a efetividade da proposta de capacitação em pauta.

Para alguns professores a participação na formação foi uma primeira oportunidade de se discutir sobre saúde mental, notadamente a infantil, e não houve a intenção de esgotar conteúdos, considerando a complexidade do campo e a diversidade do público.

A proposta deve ser compreendida como um gatilho para que os professores possam reconhecer e refletir sobre a saúde mental em seu campo de trabalho e se mobilizar para buscas e aprofundamentos. Complementarmente, sugere-se que ações desta natureza possam ser também consideradas para serem desenvolvidas em outros formatos e de forma continuada, visando tanto o acompanhamento e apoio, como a oportunidade de aprofundamento.

\section{REFERENCIAS}

1. Lykouropoulos CB, Péchy SH. O que é um CAPSi. In: Lauridsen-Ribeiro E, Lykouropoulos CB, organizadores. O CAPSi e o desafio da gestão em rede. São Paulo: Editora Hucitec; 2016. p. 8799.

2. Milanesi JB. Organização e funcionamento das salas de recursos multifuncionais em um município paulista [Internet]. [dissertação]. São Carlos, SP: Universidade Federal de São Carlos; 2012 [citado em 27 dez 2020]. 183p. Disponível em: https://repositorio.ufscar.br/handle/ufscar/3101?show=full

3. Conselho Nacional de Educação (Brasil). Resolução CNE/CEB no 4, de 2 de outubro de 2009. Institui Diretrizes Operacionais para o Atendimento Educacional Especializado na Educação Básica, modalidade Educação Especial [Internet]. Brasília, DF; 2009 [citado em 12 jan 2020]. Disponível em: http://portal.mec.gov.br/dmdocuments/rceb004_09.pdf

4. Semeghini GF, Taño BL, Matsukura TS. Inserção escolar, construção do diagnóstico e direitos de crianças e adolescentes em sofrimento psíquico sob a ótica de seus familiares. Rev FSA [Internet]. 2018 [citado em 27 dez 2019]; 15(2):156-75. Disponível em: http://www4.fsanet.com.br/revista/index.php/fsa/article/view/1541.

DOI: http://dx.doi.org/10.12819/2018.15.2.9

5. Taño BL, Hayashi MCP. Saúde mental infantojuvenil e educação: análise bibliométrica da produção científica nacional e internacional (1968-2014). RECIIS (Online) [Internet]. 2015 
[citado em 27 dez 2019]; 9(3):1-26. Disponível em: https://www.reciis.icict.fiocruz.br/index.php/reciis/article/view/989.

DOI: http://dx.doi.org/10.29397/reciis.v9i3.989

6. Taño BL. A constituição de ações intersetoriais de atenção às crianças e adolescentes em sofrimento psíquico [Internet]. [tese]. São Carlos, SP: Universidade Federal de São Carlos; 2017 [citado em 20 jan 2020]. 260p. Disponível em: https://repositorio.ufscar.br/handle/ufscar/8803

7. Guarido R. A medicalização do sofrimento psíquico: considerações sobre o discurso psiquiátrico e seus efeitos na educação. Educ Pesqui. [Internet]. 2007 [citado em 20 jan 2020]; 33(1):151-61. Disponível em: https://www.scielo.br/scielo.php?pid=S151797022007000100010\&script=sci_arttext. DOI: https://doi.org/10.1590/S151797022007000100010

8. World Health Organization. Mental health action plan 2013-2020 [Internet]. Geneva: World Healt Organization; 2013 [citado em 12 jan 2020]. Disponível em: http://apps. who.int/iris/bitstream/10665/89966/1/9789241506021_eng.pdf

9. Cid MFB, Squassoni CE, Gasparini DA, Oliveira FLH. Saúde mental infantil e contexto escolar. Pro-posições [Internet]. 2019 [citado em 15 jan 2020]; 30:1-24. Disponível em: https://periodicos.sbu.unicamp.br/ojs/index.php/proposic/article/view/8656529. DOI: https://doi.org/10.1590/1980-6248-2017-0093

10. Tomé G, Matos MG, Camacho I, Gomes P, Reis M, Branquinho CS. Mental health promotion in school context: validation of the ES'COOL scale for teachers. J Psychiatry Behav Sci. [Internet]. 2018 [citado em 21 maio 2020]; 2:1009. Disponível em: https://repositorio.ul.pt/handle/10451/37767. DOI: 10.33582/2637-8027/1009

11. Soares AGS, Estanislau G, Brietzkell E, Lefèvre F, Bressan RF. Percepção de professores de escola pública sobre saúde mental. Rev Saúde Pública [Internet]. 2014 [citado em 27 dez 2019]; 48(6):940-8. Disponível em: https://www.scielo.br/pdf/rsp/v48n6/pt_0034-8910-rsp-48-60940.pdf. DOI:10.1590/S0034-8910.2014048004696

12. Pereira CA. Capacitação em saúde mental para professores do ensino fundamental e seu impacto no ambiente escolar [Internet]. [dissertação]. São Paulo: Universidade de São Paulo; 2013 [citado em 20 jan 2020]. 173p. Disponível em: https://www.teses.usp.br/teses/disponiveis/5/5142/tde-04022014-113920/pt-br.php. DOI: 10.11606/D.5.2013.tde-04022014-113920

13. Duarte KL, Souza EM, Rodrigues L. Importância e desafios do trabalho em rede entre a escola e um serviço de saúde mental infantojuvenil brasileiro. Rev Psicol Criança Adolesc. [Internet]. 2018 [citado em 21 maio 2020]; 8(1):155-71. Disponível em: http://revistas.lis.ulusiada.pt/index.php/rpca/article/view/2484

14. Oliveira MF, Mendonça J. O CAPSi e a rede ampliada: intersetorialidade. In: LauridsenRibeiro E, Lykouropoulos CB, organizadores. O CAPSi e o desafio da gestão em rede. São Paulo: Editora Hucitec; 2016. p. 193-207.

15. Leiva L, George M, Antivilo A, Squicciarini AM, Sionsohn A, Vargas B, et al. Salud mental escolar: logros de una intervención preventiva en salud mental en niños y niñas del primer ciclo de enseñanza básica. Psicoperspectivas [Internet]. 2015 [citado em 20 jan 2020]; 14(1):31-41. Disponível em: https://scielo.conicyt.cl/pdf/psicop/v14n1/art04.pdf. DOI: http://dx.doi.org/10.5027/psicoperspectivas-Vol14-Issue1-fulltext-508

16. Vieira MA. Capacitação de professores de uma escola pública de São Paulo visando a identificação e encaminhamento de adolescentes com problemas de saúde mental [Internet]. [tese]. São Paulo, SP: Universidade Federal de São Paulo; 2012 [citado em 27 dez 2020]. 131p. Disponível em: http://repositorio.unifesp.br/handle/11600/22964

17. Sampieri RH, Collado CF, Lúcio PB. Metodologia de pesquisa. São Paulo: McGrab-Hill; 2006.

18. Bardin L. Análise de conteúdo. Lisboa: Edições 70; 2016. 
19. Vieira TB, Ramos FAC, Rosário MC. Processos educativos em saúde mental de crianças e adolescentes. In: Lauridsen-Ribeiro E, Lykouropoulos CB, organizadores. 0 CAPSi e o desafio da gestão em rede. São Paulo: Editora Hucitec; 2016. p. 54-65.

20. Pasian MS, Mendes EG, Cia F. Atendimento educacional especializado: aspectos da formação do professor. Cad Pesqui. [Internet]. 2017 [citado em 27 dez 2019]; 47(165):964-81. Disponível em: https://www.scielo.br/j/cp/a/VNYB7zVGB4YM33xLLmyG4tv/?lang=pt\&format=pdf. DOI: https://doi.org/10.1590/198053144242

21. Chaves F, Caliman LV. Entre saúde mental e escola: a gestão autônoma da medicação. Rev Polis Psique [Internet]. 2017 [citado em 21 maio 2020]; 7(3):136-60. Disponível em: https://www.seer.ufrgs.br/PolisePsique/article/view/75328.

DOI: https://doi.org/10.22456/2238-152X.75328

22. Matos RL, Goes NF. Educação especial e saúde mental infantojuvenil: inclusão e seus descaminhos. Plurais [Internet]. 2019. [citado em 24 jan 2021]; 3(3):12-7. Disponível em: https://www.revistas.uneb.br/index.php/plurais/article/view/5613

23. Duarte KL, Souza EM, Rodrigues L. Importância e desafios do trabalho em rede entre a escola e um serviço de saúde mental infantojuvenil brasileiro. Rev Psicol Criança Adolesc. [Internet]. 2017 [citado em 24 jan 2021]; 8(1):155-71. Disponível em: http://revistas.lis.ulusiada.pt/index.php/rpca/article/view/2484/pdf

Editora Associada: Vania Del Arco Paschoal

\section{CONTRIBUIÇ̃̃ES}

Carolina Elisabeth Squassoni contribuiu na concepção, coleta, organização e análise dos dados. Sarah Raquel Almeida Lins participou da concepção, coleta e análise de dados e redação. Thelma Simões Matsukura atuou na concepção, análise de dados, redação e revisão.

\section{Como citar este artigo (Vancouver)}

Squassoni CE, Lins SRA, Matsukura TS. Saúde mental infantojuvenil: avaliação de formação continuada junto a professores de sala de recursos multifuncionais. REFACS [Internet]. 2021 [citado em inserir dia, mês e ano de acesso]; 9(Supl. 2):714-723. Disponível em: inserir link de acesso. DOI: inserir link do DOI

\section{Como citar este artigo (ABNT)}

SQUASSONI, C. E.; LINS, S. R. A.; MATSUKURA, T. S. Saúde mental infantojuvenil: avaliação de formação continuada junto a professores de sala de recursos multifuncionais. REFACS, Uberaba, MG, v. 9, Supl. 2, p. 714-723, 2021. DOI: inserir link do DOI. Disponível em: inserir link de acesso. Acesso em: inserir dia, mês e ano de acesso.

\section{Como citar este artigo (APA)}

Squassoni, C.E., Lins, S.R.A., \& Matsukura, T.S. (2021). Saúde mental infantojuvenil: avaliação de formação continuada junto a professores de sala de recursos multifuncionais. REFACS, 9(Supl. 2), 714-723. Recuperado em inserir dia, mês e ano de acesso de inserir link de acesso. DOI: inserir link do DOI. 